Elsevier Editorial System(tm) for Tribology International

Manuscript Draft

Manuscript Number:

Title: TiCxOy THIN FILMS FOR DECORATIVE APPLICATIONS: TRIBOCORROSION MECHANISMS AND SYNERGISM

Article Type: TriboCorrosion Special Issue

Section/Category:

Keywords: Tribocorrosion, wear mechanisms, wear debris, wear-corrosion volume, synergistic effect

Corresponding Author: Dr Mathew.T. Mathew, PhD

Corresponding Author's Institution: University of Minho

First Author: Mathew.T. Mathew, PhD

Order of Authors: Mathew.T. Mathew, PhD; Edith Ariza, PhD; Luis.A. Rocha, PhD; A.C. Fernandes; Filipe Vaz, PhD

Manuscript Region of Origin:

Abstract: Recently, tribocorrosion is widely accepted as an interdisciplinary area of research and such studies on various materials is gaining more attention by scientists and engineers due to its practical and economical significances in a wide range of applications. Hence the main objective of present work was to investigate the tribocorrosion behavior of single layered titanium oxycarbide, $\mathrm{TiCxOy}$, thin films on a reciprocating sliding tribometer, and in the presence of artificial sweat solution at room temperature. Such films can be used as decorative coating on various components.

The films were produced by dc reactive magnetron sputtering, using $C$ pellets incrusted in the Titarget erosion area. A gas atmosphere composed of $\mathrm{Ar}$ and $\mathrm{O} 2$ was used. The Ar flow was kept constant, and the 
oxygen gas flow varied from 0 to $10 \mathrm{sccm}$. During the wear tests both the open circuit potential and the corrosion current were monitored. Also, Electrochemical Impedance Spectroscopy (EIS) tests were performed before and after sliding in order to evaluate, in detail, the modification of the protective character of the coating introduced by the joint action of wear and corrosion. The modifications of the coating microstructure and/or chemical composition induced by the variation of the deposition parameters were also evaluated and correlated with the wear-corrosion mechanisms occurring in each system. The effect of hardness, film thickness and structure of the films on the tribocorrosion performance of the coating, as a function of oxygen fraction was studied and an attempt was made to classify them. Further, individual and synergistic effects of wear and corrosion on total wear loss were estimated and correlated with tribocorrosion mechanisms. 


\title{
TiC $_{\mathrm{x}} \mathrm{O}_{\mathrm{y}}$ THIN FILMS FOR DECORATIVE APPLICATIONS:
} TRIBOCORROSION MECHANISMS AND SYNERGISM

\author{
M.T. Mathew ${ }^{1}$, E. Ariza ${ }^{1}$, L. A. Rocha ${ }^{1,2}$, A.C. Fernandes ${ }^{3}$, F. Vaz $^{3}$ \\ ${ }^{1}$ Research Centre on Interfaces and Surfaces Performance, Azurém, 4800-058 \\ Guimarães, Portugal \\ ${ }^{2}$ Universidade do Minho, Dept. Eng. Mecânica, Azurém, 4800-058 Guimarães, \\ Portugal \\ ${ }^{3}$ Universidade do Minho, Dept. Física, Azurém, 4800-058 Guimarães, Portugal
}

\begin{abstract}
Recently, tribocorrosion is widely accepted as an interdisciplinary area of research and such studies on various materials is gaining more attention by scientists and engineers due to its practical and economical significances in a wide range of applications. Hence the main objective of present work was to investigate the tribocorrosion behavior of single layered titanium oxycarbide, $\mathrm{TiC}_{\mathrm{x}} \mathrm{O}_{\mathrm{y}}$, thin films on a reciprocating sliding tribometer, and in the presence of artificial sweat solution at room temperature. Such films can be used as decorative coating on various components.

The films were produced by dc reactive magnetron sputtering, using $\mathrm{C}$ pellets incrusted in the Ti target erosion area. A gas atmosphere composed of $\mathrm{Ar}$ and $\mathrm{O}_{2}$ was used. The Ar flow was kept constant, and the oxygen gas flow varied from 0 to 10 sccm. During the wear tests both the open circuit potential and the corrosion current were monitored. Also, Electrochemical Impedance Spectroscopy (EIS) tests were performed before and after sliding in order to evaluate, in detail, the modification of the protective character of the coating introduced by the joint action of wear and corrosion. The modifications of the coating microstructure and/or chemical
\end{abstract}


composition induced by the variation of the deposition parameters were also evaluated and correlated with the wear-corrosion mechanisms occurring in each system. The effect of hardness, film thickness and structure of the films on the tribocorrosion performance of the coating, as a function of oxygen fraction was studied and an attempt was made to classify them. Further, individual and synergistic effects of wear and corrosion on total wear loss were estimated and correlated with tribocorrosion mechanisms.

Key words: Tribocorrosion, wear mechanisms, wear debris, wear-corrosion volume, syn ergistic effect.

\section{Nomenclature:}

$\mathrm{C}_{\mathrm{O}}$ : Oxygen fraction

$\mathrm{C}_{\mathrm{C}}:$ Carbon fraction

$f_{\mathrm{O}}$ : Notations of the films considered in the current work $\left(f_{\mathrm{O}}=\mathrm{C}_{\mathrm{O}} /\left(\mathrm{C}_{\mathrm{O}}+\mathrm{C}_{\mathrm{C}}\right)\right.$

SCE : Standard calomel electrode

EIS : Electrochemical spectroscopy impedance

OCP: Open circuit potential $(\mathrm{mV})$

$\mathrm{E}_{\text {corr }}:$ Corrosion potential $(\mathrm{mV})$

$\mathrm{i}_{\text {corr }}$ : Corrosion current $(\mathrm{A})$

$|\mathrm{Z}|$ : Impedance modulus

$\mathrm{R}_{\mathrm{p}}$ : Polarization resistance

$\mathrm{R}_{\mathrm{e}}$ : Electrolyte resistance

$\mathrm{C}_{\mathrm{f}}$ : Film capacitance

$\mathrm{R}_{\mathrm{pf}}:$ Film polarization resistance

$\mathrm{R}_{\mathrm{ps}}$ : Substrate polarization resistance

$\mathrm{C}_{\mathrm{dl}}$ : Double layer capacitance 
$\mathrm{R}_{\mathrm{ct}}$ : Charge transfer resistance at the interface

CPE : Constant phase element

$\varepsilon:$ Dielectric constant of the coating

$\varepsilon_{o}:$ Dielectric constant in vacuum

$A$ : Exposed area of the film $\left(\mathrm{mm}^{2}\right)$

$d$ : Thickness of the film $(\mu \mathrm{m})$

fcc : Face centered cubic

hcp : Hexagonal cubic packed

$\mathrm{K}_{\mathrm{wc}}:$ Total wear-corrosion $\left(\mathrm{mm}^{3}\right)$

$\mathrm{K}_{\mathrm{w}}$ : Wear loss due to sliding wear $\left(\mathrm{mm}^{3}\right)$

$\mathrm{K}_{\mathrm{c}}$ : Wear loss due to corrosion $\left(\mathrm{mm}^{3}\right)$

Q : The charge passed through the contact

F : Faraday's constant (96500 C.mol $\left.{ }^{-1}\right)$

$\mathrm{Z}:$ Number of electrons involved in the corrosion process

I : Total current (A)

$\mathrm{T}$ : Exposure time (s)

M: Atomic mass.

\section{Introduction}

In recent years, the studies on the processing, development and performance of thin films for decorative applications are gaining more and more importance in scientific research [1-3]. The large usage of tiny components for a wide range of applications, such as mobile phones, mobile disks etc, has significantly increased in the daily life of human beings. More than just protecting the surface, these coated 
objects need to be attractive and eye catching, but above all to guaranty the durability and keep their surface characteristics. In this particular point, corrosion and wear of the coating materials represents a major concern for manufactures.

In earlier days, metals were polish ed to decorate them, but major drawbacks of such methods are the difficulties to have large amounts of objects with the same surface characteristics and those related with oxidation and corrosion. It open ed the door to various types of other surface treatment procedures, where the use of decorative coatings is gaining more importance in modern technology [1]. Moreover a major aspiration of decorative film producers is that the films should, beyond their attractive colorations, be hard, corrosion resistant and offering wider choices of multiple color tones [2]. Since the 1990's, Physical Vapor Deposition (PVD) coating has been established as one of the highest quality finish technologies for sanitary and door hardware, among other functional and decorative objects in the US [1]. PVD coatings offer an alternative to traditional electroplating also because of environmental reasons (it is recognized as being pollution free) and several other characteristics, such as high hardness and wear resistance, no discoloration or tarnishing, high corrosion resistance and no attack of UV (Ultra-violet) radiation. Several target materials, such as zirconium, titanium, chromium, titanium-aluminium alloys and niobium, among others, can be used for coating application. Further with a multi-target system, it is also possible to make compound coatings from more than one metal [3]. By introducing reactive gases like nitrogen, methane, oxygen etc, metal-nitride, metal-carbide, metal-carbonitride and metal-oxycarbide films may also be produced with enhanced surface characteristics (mechanical, tribological, etc.) and larger range of color combinations [2-9]. 
Recently, transition-metal carbides, such as $\mathrm{TiC}$, are becoming very attractive in the field of decorative films due to their interesting mechanical and physical properties. They show high hardness and high melting point, excellent electrical and thermal conductivity, as well as high chemical and thermal stability [10-11]. Furthermore, the addition of nitrogen to these carbide films has been shown to reduce the inner stress, electrical resistivity and friction coefficients $[12,13]$. Hence, oxygen was also found to be a good candidate for the improvement of $\mathrm{TiC}$ films, due to its high reactivity with most of the metals and the variations that might be induced in the optical and mechanical characteristics of the materials, by the changes that it may cause in chemical bonding states. Therefore $\mathrm{TiC}_{\mathrm{x}} \mathrm{O}_{\mathrm{y}}$ films are expected to have a wide spread of property variations [12].

In terms of everyday life usage, decorative/protective coatings are exposed to various chemical and atmospheric conditions where they are in contact with chemical solutions such as human sweat and extraneous particles like dust. Simultaneously, they are exposed to mechanical conditions such as rubbing and holding hands. This is an area where the so-called tribocorrosion experiments may play a decisive role in order to simulate the real conditions of everyday usage. Scientifically speaking, tribocorrosion is a new area in materials research, which deals with the simultaneously mechanical (wear) and chemical (corrosion) effects on the material degradation. In recent years, such studies are becoming an emerging area because they provide a clear picture of the degradation processes, by considering various parameters that influence the material loss, even when such processes are very complex. To have an accurate picture of the basic mechanisms that are taking place, it is necessary to know the materials resistance to tribocorrosion processes such as wear and scratching, coupled with corrosion, in order to achieve desired durability and 
quality of a product that is intended to be developed for a particular application [14, $15]$.

Taking this into account, the aim of this work is to study the tribocorrosion behavior of multifunctional titanium oxycarbide thin films, $\mathrm{TiC}_{\mathrm{x}} \mathrm{O}_{\mathrm{y}}$, prepared by reactive magnetron sputtering, in artificial sweat solution, trying to bring some insights for it's possible usage as protective/decorative films. Different films were prepared by varying the oxygen flow rate. Initial experiments were carried out to study the corrosive behavior of these films and tribocorrosion experiments were done on a reciprocating tribometer. An attempt has also been made to analyze different mechanisms involved in the tribocorrosion process. The knowledge of the tribocorrosion behavior of such films definitely assists in producing better films with expected performance characteristics for several decorative components.

\section{Experimental details}

\subsection{Film preparation}

Reactive DC magnetron sputtering was used to deposit $\mathrm{TiC}_{\mathrm{x}} \mathrm{O}_{\mathrm{y}}$ films, from a $\mathrm{Ti}$ target $\left(200 \times 100 \mathrm{~mm}^{2}\right)$, with 12 cylindrical $\mathrm{C}$ pellets $(10 \mathrm{~mm}$ diameter each, occupying an average area of $1200 \mathrm{~mm}^{2}$ ) incrusted in its erosion zone. Films were deposited on polished high-speed steel (AISI M2) and single crystal silicon wafers with (100) orientation. All substrates were previously ultrasonically cleaned and sputter etched for $15 \mathrm{~min}$ in an $\mathrm{Ar}$ atmosphere (pressure of $0.15 \mathrm{~Pa}$ ). The films were prepared with the substrate holder positioned at $70 \mathrm{~mm}$ in all runs, applying a DC current density of 75 A.m ${ }^{-2}$. The Ar flow was kept constant at $60 \mathrm{sccm}$ and the oxygen gas flow varied from 0 to $10 \mathrm{sccm}$ (corresponding to a partial pressure variation between 0 and 
$8.6 \times 10^{-2} \mathrm{~Pa}$ ). The working pressure was approximately constant at $0.4 \mathrm{~Pa}$ and the substrates were grounded.

The chemical composition of the coatings was investigated by a Cameca SX-50 Electron Probe Micro Analysis (EPMA). The oxygen fraction in each sample was determined by the ratio between the oxygen content and the sum of both oxygen and carbon contents: $f_{\mathrm{O}}=\mathrm{C}_{\mathrm{O}} /\left(\mathrm{C}_{\mathrm{O}}+\mathrm{C}_{\mathrm{C}}\right)=\mathrm{X}$. The films are labeled as $f_{\mathrm{O}}=\mathrm{X}$. A short summary of all prepared samples is given in Table 1. Ball cratering tests were used to measure the thickness of the films. Surface and cross-section morphological features of the films were studied by scanning electron microscopy (SEM) and atomic force microscopy (AFM), while surface defects were characterized by optical microscopy.

\subsection{Preliminary corrosion tests}

Before starting the tribocorrosion tests, the films were under gone an individual analysis on the basic corrosion behavior by using a specially made corrosion cell. It was done by conducting open circuit potential (OCP) for $600 \mathrm{~s}$ and potentiodynamic polarization tests, in both substrate and $\mathrm{TiC}_{\mathrm{x}} \mathrm{O}_{\mathrm{y}}$ films, between $-0.8 \mathrm{~V}$ to $+2.0 \mathrm{~V}$ at

scan rate $2 \mathrm{mV} \cdot \mathrm{s}^{-1}$. The instrument used was a PGP201 Potentiostat/galvanostat (Radiomater analytical, Denmark), controlled by the Voltamaster-1 software.

\subsection{Tribocorrosion tests}

A schematic diagram of the tribocorrosion experimental set-up is shown in Fig. 1. Reciprocating sliding test apparatus, (Plint TE-67/R) was supplied by Phenoix Tribology Ltd (UK). It has facilities to perform tribological experiments, such as pin on plate/disc, or ball on plate/disc, in a controlled environment. In the present investigation, tests were conducted with an alumina pin (with a truncated cone 
geometry) on plate sample ( $\mathrm{TiC}_{\mathrm{x}} \mathrm{O}_{\mathrm{y}}$ film) at a fixed load of $5 \mathrm{~N}$, a sliding stroke length of $6 \mathrm{~mm}$ with a frequency of $1 \mathrm{~Hz}$ and an exposed area of $0.95 \mathrm{~cm}^{-2}$. The fixed $\mathrm{TiC}_{\mathrm{x}} \mathrm{O}_{\mathrm{y}}$ film was connected as the working electrode. At the beginning of each test, the pin head was polished to maintain a constant diameter of $1 \mathrm{~mm}$, and also to achieve consistent contact conditions between pin and sample. The electrolyte, artificial sweat solution was prepared according to Table 2 , with a pH of $4.49 \pm 0.01$. The solution is a simplified version of that formalised in the European Standard EN 1811:1998 [16], contained in an acrylic cell with a volume of approximately $20 \mathrm{ml}$. A standard calomel electrode (SCE) was used as the reference electrode and a platinum wire was used as a counter electrode.

Prior to all tribocorrosion experiments, the samples were cathodically polarized at $-900 \mathrm{mV}$ vs. SCE during $180 \mathrm{~s}$ for the purpose of cleaning. Further, and in order to stabilize the sample, a potential of $-660 \mathrm{mV}$ was applied during $600 \mathrm{~s}$. Then, electrochemical impedance spectroscopy (EIS) was performed in the frequency range of $100 \mathrm{kHz}$ to $15.82 \mathrm{mHz}$, with an ac sine wave amplitude of $10 \mathrm{mV}$ applied to the electrode, keeping the sample under potentiostatic control, i.e. $-660 \mathrm{mV}$ ( $\mathrm{E}_{\text {corr }}$ of the steel). The alumina pin was brought in contact with the plate sample. The reciprocating sliding tests were conducted during $3600 \mathrm{~s}$. To achieve electrochemical stabilization of the samples before and after the real sliding process, a potential of $660 \mathrm{mV}$ was applied for a period of $180 \mathrm{~s}$. After the stabilization, the pin was removed from contact with the sample, which was left stabilizing, at the same potential, during $600 \mathrm{~s}$, followed by another EIS test. At the end of the test, pin and sample were ultrasonically cleaned by propanol and distilled water. Each experiment was repeated twice, and one set of the test $\left(f_{\mathrm{O}}=0.92\right)$ was repeated three times to estimate the expected error (5-7\%) in the tests. For EIS data simulation the Z-View 
software was used. The wear volume was determined by profilometry, using a Perthometer S5P surface measuring and recording instrument, by measuring the cross-sectional area and stroke length. The cross sectional area and depth of the wear profiles were measured with the help of Autocad 2006.

\section{Results and Disc ussion}

\subsection{Surface and morphological cha racterization}

The worn surfaces were studied by using optical microscopy, SEM and AFM images. An AFM image obtained for the film with $f_{\mathrm{O}}=1$ is shown in Fig. 2(a). An AFM image of a corrosion pit formed on the surface of the film with $f_{\mathrm{O}}=0.97$ is also shown in Fig. 2(b). The micrographs obtained by optical microscopy (Fig. 2(c) and (d)), show the corroded surfaces of films with $f_{\mathrm{O}}=0.33$ and $f_{\mathrm{O}}=0.97$, illustrating the pitting process after the polarization test.

Representative SEM images of the worn surfaces are shown in Fig. 3(a-f). Fig. 3(a) shows the pin path and worn surface on the film with $f_{\mathrm{O}}=0.35$. It is worth to observe the presence of a special region, close to the boundary of the pin path (Fig. 3(b)), which may be the result of corrosion attack and that may lead to cracking and removal of the films in small fragments. Fig. 3(c) shows the clear boundary of the worn surface of the film with $f_{\mathrm{O}}=0.67$. Worn surfaces of the films with $f_{\mathrm{O}}=0.33, f_{\mathrm{O}}=$ 0.92 and $f_{\mathrm{O}}=1$ are shown in Fig. 3(d), (e) and (f) respectively. They demonstrate the

presence of four regimes on the worn surface, i.e., A, B, C and D, which will be discussed further in section 3.8 . 


\subsection{Initia I corrosion tests}

In Fig. 4, an overlap of the potentiodynamic polarization curves obtained for some representative $\mathrm{TiC}_{\mathrm{x}} \mathrm{O}_{\mathrm{y}}$ films (films with $f_{\mathrm{O}}=0.33, f_{\mathrm{O}}=0.97$ and $f_{\mathrm{O}}=1$ ) are presented. The polarization curve of the M2 steel, used as substrate, is also plotted. The first important note is that the films clearly show good corrosion resistance, compared to the substrate material. In fact, the results of potentiodynamic polarization tests, shown in Fig. 4, reveal that the corrosion resistance of the substrate is clearly improved by the deposition of the films. In all cases the corrosion current density of the films, $i_{\text {corr, }}$ is below $1 \mu \mathrm{A} . \mathrm{cm}^{-2}$, which is significantly lower than that of the substrate $\left(\mathrm{i}_{\text {corr }}=3.47 \mu\right.$ A.cm $\left.{ }^{-2}\right)$. A pitting potential is observed in all films.

As stated above, the presence of pits after the polarization tests was examined by optical microscopy, AFM and SEM analysis and correlated with the pitting behaviour (see Fig. 2(c), (d) and Fig 3(b)). The film with $f_{\mathrm{O}}=0.33$ shows the highest pitting potential, followed, in decreasing order, by the films with $f_{\mathrm{O}}=1$ and $f_{\mathrm{O}}=0.97$, indicating that a better pitting corrosion resistance is present in the film with the lowest oxygen fraction. These results indicate that, similarly to what has been observed for the film's physical and mechanical properties $[4,14,15,18]$, the composition of the samples and the consequent structural/morphological changes are also ruling its corrosion behavior. In fact, in the $f_{\mathrm{O}}=0.33$ film, a small and almost imperceptible quantity of pits was observed after the polarization test (Fig. 2(c)), when compared to the $f_{\mathrm{O}}=0.97$ film (Fig. 2(d)). The amount of surface defects of the as-produced films might have some influence on the pitting initiation stage. In fact, as shown in Table 1 , the sample with $f_{\mathrm{O}}=0.33$ shows almost no surface defects when observed by optical microscopy. However, the lowest pitting potential was observed in the film with $f_{\mathrm{O}}=0.97$, which presented a lower number of defects (99 
deffects $/ \mathrm{mm}^{2}$ in comparison with the $596 \mathrm{deffects} / \mathrm{mm}^{2}$ for the film with $f_{\mathrm{O}}=1$ ). This result suggests that other parameters, related to the structure of the films, were affecting the corrosion behavior. Also, no direct correlation between film thickness and corrosion behavior ( $i_{\text {corr }}$ or pitting potential) could be established (see Table 1 and Fig. 4), which again reinforces the latter assumption.

Interestingly, films with $f_{\mathrm{O}}=0.97$ and $f_{\mathrm{O}}=1$ show two distinct passive regions. This phenomenon is not completely clarified, but it can be related to a preferential dissolution of anatase and rutile $-\mathrm{TiO}_{2}$ phases in this kind of films. In fact, as described by Fernandes et al [18], while the $f_{\mathrm{O}}=0.33$ film, presenting the lowest oxygen fraction, is basically constituted by a mixture of fcc $\mathrm{Ti}$ and fcc $\mathrm{TiC}$ phase, these last two films $\left(f_{\mathrm{O}}=0.97\right.$ and $\left.f_{\mathrm{O}}=1\right)$, with the highest oxygen fractions, are mainly characterized by the presence of a mixture of poorly crystallized rutile and anatase phases of $\mathrm{TiO}_{2}$. Further explanations of structural variation on the observed behaviour are addressed in section 3.9.

\subsection{Tribocorrosion performance}

The evolution of the current density and friction coefficient during the tribocorrosion tests, for each film, was analyzed. Fig. 5 shows representative curves of the observed trends: (a) for the film with $f_{\mathrm{O}}=0.55$ and (b) for the film with $f_{\mathrm{O}}=0.79$. As it can be observed in the graph, (Fig 5(a)) the current density decreases with the increase in the sliding time. The increase in the exposed area and accumulation of wear debris in the contact zone can be the reasons for the reduction in the current density during the sliding process.

Studies on tribocorrosion behavior of $\mathrm{Fe}-1 \mathrm{Cr}$ in acid and alkaline solutions reported that in a reciprocating sliding tribometer, the instantaneous current is a 
periodic function, depending on the pin motion, which moves at a constant speed during a forward stroke and then remains stationary for a few milliseconds before changing its direction [19]. It was observed that during the rest period, the current decreases due to repassivation, and then increases again when the pin starts to return. The electrochemical behavior of the films in the current study will surely be influenced by such non-steady state and unstable experimental conditions.

Pontiaux et al. [20] also suggested that the main concern in wear-corrosion studies on the current set-up is that the reciprocating pin motion creates non-steady electrochemical conditions at the contact zone. However, by knowing the fact that, electrochemical interfacing techniques favor stationary conditions to produce better results, the dynamic and transient condition at the contact zone should/might influence the obtained results.

In the case of the system under evaluation in this work, friction coefficient values are observed to be very sensitive to the sliding process. Generally, the values of friction coefficients remain stable after an initial running-in period. This is the case in the film with $f_{\mathrm{O}}=0.55$, (Fig. 5(a)). However, in some cases, there was a gradual increment in the values of friction coefficients after the first half of the test. As an example, the case of the film with $f_{\mathrm{O}}=0.79$, (Fig. 5(b)). The increase in the friction coefficient during sliding was also reported in earlier studies, and it is suggested that such behavior may be due to the presence of corrosion products and wear debris formed during the sliding process [14]. Further, the close observation on the Fig. 5(a) \& (b), (marked as A and B), shows that the increase in friction coefficient is accompanied by the decrease and/or fluctuations in corrosion current, which is ensuring the existence of such situation in the current study. However, additional 
analysis is required to gain more understanding on such interesting tribocorrosion phenomena and associated effects on the material degradation process.

\subsection{Elect rochemical impedance spectroscopy (EIS) analys is}

In Fig 6, results of EIS tests for some representative $\mathrm{TiC}_{\mathrm{x}} \mathrm{O}_{\mathrm{y}}$ films $\left(f_{\mathrm{O}}=0.33, f_{\mathrm{O}}=\right.$ 0.97 and $\left.f_{\mathrm{O}}=1\right)$ before and after sliding processes are presented. Fig. $6(\mathrm{a})$ shows the Bode $\mathrm{Z}$ plot (Frequency vs. Impedance modulus $|\mathrm{Z}|)$, while Fig. 6(b) shows the Bode phase plot (Frequency vs. Phase angle).

Results of EIS data simulations are presented in Fig. 7. In all cases it was assumed a electrochemical equivalent circuit composed by the electrolyte resistance $\left(R_{e}\right)$ in series with one pair of elements in parallel. This pair of elements represents the dielectric properties of the film, and is composed of the film capacitance $\left(\mathrm{C}_{\mathrm{f}}\right)$ and by the film polarization resistance $\left(\mathrm{R}_{\mathrm{pf}}\right)$. An exception occurs with the film with $f_{\mathrm{O}}=1$ in which a second pair of elements was added in series with the first one. This last electrical pair is related to the processes occurring at the electrolyte/substrate interface and is composed of the same electric elements: the double layer capacitance $\left(\mathrm{C}_{\mathrm{dl}}\right)$ and the charge transfer resistance at the interface $\left(R_{c t}\right)$. In both equivalent circuits a constant phase element (CPE) was used to replace the pure one, which rarely occurs in a real process. A good agreement between the fitted and the experimental data was obtained.

Fig. 7(a) shows the evolution of the film thickness and of the polarization resistance $\left(R_{p}\right)$ estimated before and after the sliding tests as a function of oxygen fraction $\left(f_{\mathrm{O}}\right)$. In the case of the film with $f_{\mathrm{O}}=1, \mathrm{R}_{\mathrm{p}}$ was calculated by the sum of $\mathrm{R}_{\mathrm{ps}}$ (substrate polarization resistance) and $\mathrm{R}_{\mathrm{pf}}$ (film polarization resistance) as generally assumed as frequency tends to zero and assuming that $R_{p s}+R_{p f}>0$ [17]. 
Additionally, Fig. 7(b) presents the evolution of the film thickness and the film capacitance $\left(\mathrm{C}_{\mathrm{f}}\right)$ estimated before and after sliding tests, as a function of $f_{\mathrm{O}}$. Finally, Fig. 7(c) shows the evolution of the number of defects and $R_{p}$ before and after the sliding process as a function of the $f_{\mathrm{O}}$.

As it can be observed in Fig. 6, EIS spectra, the electrochemical behavior of the films is slightly altered after the sliding process, showing the good corrosion behavior at the tested potential. An important characteristic to be mentioned is the presence of a clear second time constant in the case of the film with $f_{\mathrm{O}}=1$ (see Fig. 6(b)), which is probably related to the large number of defects present in this film (see Table 1). Nevertheless this behavior is quite similar for both $f_{\mathrm{O}}=1$ and $f_{\mathrm{O}}=0.97$, which are the films with the highest impedance (see Fig. 6(a)). This result shows that the films produced with higher oxygen fractions have better corrosion behavior. However, it should be noted that the diverse pitting corrosive behaviour, see section 3.2, also should be a factor in determining the best film. Again the different structural features revealed by these films (developing highly insulating oxide type structures in comparison to metallic hep Ti and fcc-based $\mathrm{Ti}(\mathrm{O}, \mathrm{C})$ in the others [18]), are playing a fundamental role for such behaviour.

After EIS data simulation, Fig. 7(a), an apparent general trend of an improvement of the polarization resistance with the increase in the oxygen fraction is detected. Results show, as already mentioned, that the $R_{p}$ of the films at the evaluated potential (-660 mV, i.e., corrosion potential of the steel substrate, $-600 \mathrm{mV}$ vs. SCE, but a cathodic potential regarding the films, (see Fig. 4) has slightly changed after the sliding; only the film with $f_{\mathrm{O}}=0.55$ shows a clear decrease of the $\mathrm{R}_{\mathrm{p}}$ after the sliding time. This suggests that at this potential the wear/corrosion process does not affect significantly the performance of the films, revealing their good corrosion behavior. 
The high value of $\mathrm{R}_{\mathrm{p}}$ obtained in the film with $f_{\mathrm{O}}=1$, showing the lowest thickness and very low $\mathrm{R}_{\mathrm{pf}}$ value (200 ohm.cm², as calculated by EIS data simulation), is mainly due to the higher $\mathrm{R}_{\mathrm{ct}}$ revealed by the film. In fact, SEM analysis of the film shows the most compact structure at the film/substrate interface providing a higher $\mathrm{R}_{\mathrm{ct}}$, and consequently a higher $R_{p}$ value. On the other hand, the lower $R_{p f}$ value can be related to the high quantity of porosity existing in this film (see Table 1).

As mentioned above, the $\mathrm{C}_{\mathrm{f}}$ and $\mathrm{R}_{\mathrm{pf}}$ values are related to the dielectric properties of the films. Also, it is known that $\mathrm{C}_{\mathrm{f}}=\varepsilon \varepsilon_{0} \mathrm{~A} / \mathrm{d}$, where $\varepsilon$ is the dielectric constant of the coating, $\varepsilon_{o}$ is the dielectric constant in vacuum, $A$ is the exposed area of the film and $d$ is the thickness of the film. As it can be observed in Fig. 7(b), results suggest that the film thickness appears not to have a clear influence on the capacitance of the film but the main difference between the films can be due to their different physical properties, including the structure and the dielectric constants. In fact, films with higher oxygen fraction, especially that with $f_{\mathrm{O}}=1$, reveal the lowest $\mathrm{C}_{\mathrm{f}}$, which can be related to the comparatively low dielectric constant characteristic of the rutile and anatase phases of the $\mathrm{TiO}_{2}$, when compared with the other more metallic-type films. In fact, high insulated properties, i.e., high electrical resistivity was measured in this film and others with similar characteristics (prepared with higher oxygen flows, and revealing oxide-type structures) [18]. Also, it is important to mention that the small changes observed in $\mathrm{C}_{\mathrm{f}}$ after sliding (see Fig. 7(b)), show the good protective character and the low degradation suffered by the films after sliding tests.

Finally, it should be emphasize that in accordance with the electrochemical polarization results, EIS results showed that the corrosion properties do not have a clear dependence from the film thickness and/or the presence of defects as it can be observed in Fig. 7(a) and (c). These results support the idea that corrosion properties 
are primarily dependent on the structural properties of the films and further explanations are given in section 3.9.

\subsection{The variation in wear-corrosion volume loss as a function of oxygen fraction}

The variation of total wear loss due to mechanical (wear) and chemical (corrosion) effects (which can be termed as $\mathrm{K}_{\mathrm{wc}}$, with further explanations given in next section), for the various films that are considered in the test, is shown in Fig. 8. It is clear that the main trends in the variation of wear-corrosion volume loss with oxygen fraction can be distinguished within four zones. The films corresponding to low oxygen fractions (with a metallic-like Ti(C,O) fcc-type structure and hcp Ti [18]) exhibit high wear volume loss and further demonstrate a reduction zone, (zone I), within the range $f_{\mathrm{O}}=0.3$ to 0.5 , Fig. 8 . Additionally, there is a stabilized zone II, for films with an oxygen fraction varying between 0.5 and 0.8 , followed by an increasing zone III, corresponding to oxygen fractions of 0.8 to 0.9 . For oxygen fractions above 0.9 , a sudden reduction in wear volume loss is revealed, zone IV. It can be noted that the distribution of the above zones is matching with the structural variation of the films as a function of oxygen fraction [18] and more details are given in section 3.9.

Furthermore, the graph also shows that the hardness and film thickness does not have much influence on wear volume loss, which is against what one would expect [21]. For instance, the film with maximum thickness, i.e., that with $f_{\mathrm{O}}=0.33$ shows higher wear volume and the film with minimum thickness, i.e., $f_{\mathrm{O}}=1$ shows the lowest wear volume loss. To further analyze the results, the depth of the worn profile was estimated and compared with thickness (Fig. 8), which may help to identify if the film was removed completely after the tribocorrosion test. It is obvious that most of the films are not removed completely. This shows that this film system (when we 
considered film and substrate as a integrated body) exhibit good performance in contrast with other thin films, for instance decorative $\mathrm{ZrO}_{\mathrm{x}} \mathrm{N}_{\mathrm{y}}$ films, which have been previously investigated in the group [14]. Further explanation on the effect of thickness is addressed in next section 3.6.

\subsection{Classification of the films based on tribocorrosion behaviour.}

In order to gather the general tribocorrosion behaviour of the films or rather film system from the current study, a methodology was adopted as illustrated below. As it was observed in the previous section (3.5), the films can be easily classified in to two sets, one set which is without any retention of the film after the tribocorrosion test and another set that retains film, as shown in the schematic diagram, (Fig. 9(a) and (b)). The films with $f_{\mathrm{O}}=0.35, f_{\mathrm{O}}=0.97$ and $f_{\mathrm{O}}=1$ belong to the former set and the other five films correspond to the latter set. It is clear that in order to do such analyze on the performance of the films based on the thickness, it is necessary to have all the films in one category. However, in the present study the film thickness is also a variable. Moreover, it was observed that more than the thickness, structure of the films has a strong influence on the tribocorrosion behaviour. Hence it is very difficult to classify or recommend the best films that are considered in the test.

In another perception, it is also very clear that the samples that retain film are really showing the performance of the film system against tribocorrosion. As it would be expected the wear volume loss depends on the thickness, structure and hardness and other properties of the films. Hence it can be concluded that there would be a critical thickness for the films, having better structure and other properties favorable to tribocorrosion resistance. However, it may be too early for such conclusion as in the current study was focused on the influence of oxygen fraction; the above 
parameters are also variables. Nevertheless, it is worth in mentioning that the novelty of the current work is the production of a new class of $\mathrm{TiC}_{\mathrm{x}} \mathrm{O}_{\mathrm{y}}$ films and study their basic tribocorrosion behaviour and mechanisms as a function of oxygen fraction. In the next stage of work, in-depth study will definitely be considered in order to draw coherent understanding of tribocorrosion behaviour of individual films as a function of film thickness, hardness and structure (see section 3.9). Hence by acknowledging the limitation of the study and based on the current results on the wear volume loss, thickness of the film and depth of the wear profile, Fig. 8, it is clear that the films with $f_{\mathrm{O}}=0.55$ and $f_{\mathrm{O}}=0.79$ show good performance compared to the others.

\subsection{Analysis on synergistic effects of wear and corrosion}

In tribocorrosion studies, it is necessary to estimate the individual contribution of wear and corrosion to understand their synergistic or antagonistic effects on the total material removal. As observed in the last section (section 3.5), five samples retain the films after one hour of sliding. Hence, those films are selected for the further analys is on the synergistic effects of wear and corrosion.

The total wear-corrosion volume loss may be explained by defining the following terms, using methodology developed by Yue and Shi [22], in the wear-corrosion analysis. If:

$$
\mathrm{K}_{\mathrm{wc}}=\mathrm{K}_{\mathrm{w}}+\mathrm{K}_{\mathrm{c}}
$$

where $\mathrm{K}_{\mathrm{wc}}$ is the total wear-corrosion, $\mathrm{K}_{\mathrm{w}}$ is the total wear loss due to sliding wear and $\mathrm{K}_{\mathrm{c}}$ is due to corrosion. 
The results of the various contributions to wear volume loss are given in Table 3 and Fig. 10. The volume loss due to the corrosion, $\mathrm{K}_{\mathrm{c}}$, is derived using Faraday's law, e.g.:

$$
\begin{aligned}
\mathrm{K}_{\mathrm{c}} & =\mathrm{Q} / \mathrm{ZF} \\
\mathrm{K}_{\mathrm{c}} & =\mathrm{MIt} / \mathrm{ZF}
\end{aligned}
$$

where ' $Q$ ' is the charge passed, ' $F$ ' is Faraday's constant (96500 C.mol' ${ }^{-1}$ ), ' $Z$ ' is the number of electrons involved in the corrosion process, ' $\mathrm{I}$ ' is the total current, ' $\mathrm{t}$ ' the exposure time and ' $\mathrm{M}$ ' is the atomic mass of the material.

As stated above, in the current study, the tests were conducted at a potential of $660 \mathrm{mV}$ vs. SCE, which lies in the immune or cathodic region of polarization curves, (Fig. 4). Hence, it is not surprising to observe that the $\mathrm{K}_{\mathrm{c}}$ values are very small or rather negligible in comparison with $\mathrm{K}_{\mathrm{w}}$, which are almost equal to $\mathrm{K}_{\mathrm{wc}}$, (Fig. 10). Generally, there is an increasing trend in the case of $\mathrm{K}_{\mathrm{c}}$, as oxygen fraction increases except for the film with $f_{\mathrm{O}}=0.67$. It can be speculated that such special behaviour of the films is the result of the influence of variation in film structure [18], as indicated in the earlier sections.

In order to understand the synergistic effects, $\mathrm{K}_{\mathrm{c}} / \mathrm{K}_{\mathrm{w}}$ ratio was estimated, as shown in Table 3. As it is observed from the literature, Stack et al, in their extensive studies on erosion-corrosion and wear-corrosion have established various regimes to identify the dominating mechanisms in the tribocorrosion process [23-25]. The major criteria are listed below.

$$
\begin{array}{cl}
\mathrm{K}_{\mathrm{c}} / \mathrm{K}_{\mathrm{w}} \leq 0.1 & \text { (wear) } \\
0.1<\mathrm{K}_{\mathrm{c}} / \mathrm{K}_{\mathrm{w}} \leq 1 & \text { (wear- corrosion) } \\
1<\mathrm{K}_{\mathrm{c}} / \mathrm{K}_{\mathrm{w}} \leq 10 & \text { (corrosion- wear) }
\end{array}
$$




$$
\mathrm{K}_{\mathrm{c}} / \mathrm{K}_{\mathrm{w}}>10 \quad \text { (corrosion) }
$$

Hence, it is clear from Equation (4) and Table 3 that the tribocorrosion process in the current study is entirely dominated by wear process or mechanisms. EIS analysis, (Fig. 6 and Fig. 7), and SEM images of the worn surfaces, (Fig 3 (b-f)) also supports this conclusion. The average values of $\mathrm{K}_{\mathrm{c}}$ for the films with $f_{\mathrm{O}}=0.55$ and $f_{\mathrm{O}}=0.79$, are ind icative of their good characteristics. Furthermore and in order to understand the clear influence of synergistic effects on the tribocorrosion process, the analyses are to be conducted by varying the mechanical parameters, such as load and sliding velocity etc. [26].

\subsection{Mechanisms of wea $r$ process}

In order to analyze the mechanisms involved in the tribocorrosion process, a schematic diagram of the contact zone is shown in Fig. 11. The top view of the contact zone during the tribocorrosion process shows the presence of four regions:

$\underline{\text { Region A: }}$ Pin path (severe wear);

$\underline{\text { Region B: }}$ : Sides of the pin path, corrosion prone area, presence of wear debris (severe wear);

$\underline{\text { Region C: }}$ Corrosion prone area, collection of wear debris (low wear);

$\underline{\text { Region D: }}$ Corrosion prone area, in the boundary (low wear, cracks initiation).

It is well known that, in the case of a reciprocating sliding system, the material removal may be the result of several mechanisms, which are directly or indirectly involved in the process [22-28]. In the initial stage of the sliding, the main mechanisms that drive the material removal may be the ploughing and cutting process, which result from the strong action of the alumina pin, and high contact pressure by the applied load. 
It was also reported by other studies that the mechanisms may also be dominated by three body situations by formation of wear debris and corrosion products, which remain in the tribological contact for a certain period before they are eliminate [2833], as shown in Fig. 11. The presence of a third body in a tribological contact can have a significant effect on friction and wear behaviors based on the nature, shape and size of such particles. For instance the lubrication properties of corrosion products formed at the interface may reduce the friction coefficient by decreasing the severity of the wear [20]. It is also known that the presence of wear debris will influence the corrosion potential at the contact zone [19-20]. However in the present study the experiments were done at the $\mathrm{E}_{\text {corr }}$ of the steel, hence there is no likelihood of a predominant effect.

Furthermore, it was also observed that wear particles may stick to the alumina pin (which were clearly observed in this work on the pin head, immediately after the tests) and may result in a grooving mechanism during the film removal [29]. Further, as shown in the schematic diagram of the contact zone, Fig. 11, there are two regions (C and D) surrounded by the pin path, that are characterized by low wear. However, the cracks and pits that are initiated or formed because of the corrosion in the above regions, further lead to delamination of the films by layers, and also to severe wear due to the sudden sliding action of the pin (in regions A and B). It is also interesting to observe from SEM images, in the case of films with $f_{\mathrm{O}}=0.67$, (Fig. 3(c)), the presence of a special region on the surface of the film near the boundary. It is clear that such a region may result in high wear volume loss, by the synergetic effect of wear and corrosion as stated above. Moreover, the irregularities in the boundaries of the worn surface, (Fig. 3(d), (e) and (f)) testify to the existence of such mechanisms in all the films, considered in the test. 


\subsection{Influe nce of film structure on tribocorrosion beha viour}

As stated above (in the case of corrosion, pitting corrosion behaviour and EIS analysis, sections 3.2 and 3.4 ), the study unambiguously shows that the wearcorrosion volume loss of the films is not directly influenced by their hardness or thickness, which might be again a clear sign of the strong influence of the structure of films in such situations. The XRD analysis of the various films also clarifies the above role by demonstrating its diverse structural properties. In fact, as already mentioned, the structure of films can be divided into two main zones, with an intermediate or transition zone, depending on the particular composition of the films, especially that of oxygen [18]. Zone 1 was found to be that corresponding to the lower values of oxygen (oxygen flows below approximately $2.5 \mathrm{sccm}$ ), which resulted in films that were identified as developing a fcc phase structure that could be a mixture of $\mathrm{TiC}$ and $\mathrm{TiO}$. In the transition zone the films were characterized as being of a quasi-amorphous-type. Finally, in zone 2, the films were characterized by a mixed poorly crystallized rutile and an atase $\mathrm{TiO}_{2}$ phase, corresponding to the films that were deposited with the highest oxygen amounts (corresponding to oxygen flows above approximately $4.5 \mathrm{sccm})[18]$.

Zhang and $\mathrm{Li}$ [34] have also pointed out in their studies on the tribological behavior of tungsten coatings, that microstructure has a strong influence on wear performance, and suggested that fine closely-packed structure shows good performance due to its superior elastic behavior and high hardness. In its turn, it is well-known that the microstructure of the film is a function of film deposition parameters, substrate temperature and surface conditions etc. [35-36]. Thus, even though the wear-corrosion volume loss agrees with above structural evaluation, as mentioned earlier, there is a need of detailed analysis for further clarification on 
individual film and also by considering other parameters of films, such as thickness or hardness etc. are constant.

In the current study, the electrochemical potential used in the tribocorrosion tests has been fixed as the $\mathrm{E}_{\text {corr }}$ of the substrate material, in order to study the basic behavior of the films, by preventing the sudden dissolution effect of substrate material, M2 steel. However this is not the case in real situations. Hence, this study can be extended to analyze the tribocorrosion behavior of the films at various potentials, above $\mathrm{E}_{\text {corr }}$ of the substrate material or at the $\mathrm{E}_{\text {corr }}$ of individual films. This will assist in understanding the individual contributions from wear and corrosion and their synergistic effects on the material degradation.

\section{Conclusions}

The following conclusions can be derived from this study:

- The study shows that all the films are protecting the steel substrate, having good performance when compared with other films considered in previous work $\left(\mathrm{ZrO}_{\mathrm{x}} \mathrm{N}_{\mathrm{y}}\right.$ films $)$.

- It was found that the corrosion behavior of $\mathrm{TiC}_{\mathrm{x}} \mathrm{O}_{\mathrm{y}}$ films is closely related to the film's structural features than with the basic film characteristics, such as thickness and/or number of defects.

- The EIS measurements showed the high corrosion resistance of the $\mathrm{TiC}_{\mathrm{x}} \mathrm{O}_{\mathrm{y}}$ films, which is clear from the unchanged/constant values of the polarization resistance, before and after the sliding process, at the evaluated potential.

- The films demonstrated different behaviors in tribocorrosion tests and resulted wear-corrosion volume. Among all the studied samples, five of them did not show complete removal of the film after 1 hour of sliding duration. Hence they 
have good tribocorrosion resistance, especially the films with $f_{\mathrm{O}}=0.55$ and $f_{\mathrm{O}}$ $=0.79$. The film thickness or hardness showed no direct relationship with wear-corrosion volume loss.

- The mechanisms of the wear-corrosion process have been analyzed, and it was observed that they may be influenced by the wear particles and corrosion products at the contact zone. Also the delamination mechanism, that is initiated by the corrosion crack acts as synergetic contribution of wearcorrosion to the metal removal.

- The individual contribution of wear and corrosion and their synergistic effect on the tribocorrosion process were analyzed. It was observed that tribocorrosion process is dominated by wear process.

- The studies also show that the structure of the films is the most influential parameter (bound to the limitation of the current study) on the wear-corrosion volume loss, more than all other parameters.

\section{Acknowledgements}

The authors gratefully acknowledge the financial support of the Portuguese Science Foundation (FCT) by the contracts SFRH/BPD/20377/2004, SFRH/BPD/5518/2001 and SFRH/BD/27569/2006 and by the project $n^{\circ}$ POCTI/CTM/38086/2001 cofinanced by European community through FEDER.

\section{References}

1. M. Eerden, Products Finishing, (2003) 54-59.

2. C. Mitterer, J. Komenda-Stallmaier, P. Losbichler, P. Schmolz, W.S.M. Werner, H. Stori, Vacuum, 4611 (1995). 
3. E. Budke, J. Krempel-Hesse, H. Maidof, H. Schusler, Surface and Coatings Technology, 112 (1999) 108-113.

4. L.A. Rocha, E. Ariza, J. Ferreira, F. Vaz, E. Ribeiro, L. Rebouta E. Alves, A.R. Ramos, Ph. Goudeau, J.P. Riviere, Surface and Coatings Technology 180-181 (2004) 158-163.

5. C. Foneca, F. Vaz, M.A. Barbosa, Corrosion Science, 46 (2004) 3005-3018

6. Jian-De Gu, Pei-Li Chen, Surface and Coatings Technology 200 (2006) 33413346.

7. C. Mitterer, H.M. Ott, J. Komenda-Stallmaier, P. Schmolz, W.S.M. Werner, H. Stori, Journal of Alloys and Compounds, 239 (1996)183-192.

8. F. Vaz, P. Cerqueira, L. Rebouta, S.M.C. Nascimento, E. Alves, Ph. Goudeau, J.P. Riviere, Surface and Coatings Technology 174-175 (2003) 197-2003.

9. P.J. Kelly, R.D. Arnell, Vacuum, 56 (2000) 159-172.

10.E.L. Toth, Transition Metal Carbides and Nitrides, Academic Press, New York, 1971

11. A. Zaoui, S. Kacimi, B. Bouhafs, A. Roula, Physica B 358 (2005) 63.

12. H. Dimigen, C.P. Klages, Surface and Coatings Technology 49 (1991) 543.

13. D. Monaghan, D. Teer, P. Logan, I. Efeoglu, R. Arnell, Surface and Coatings Technology 60 (1993) 525.

14. S.C. Ferreira, E. Ariza, L.A. Rocha, J.R. Gomes, P. Carvalho, F. Vaz, A.C. Fernandes, L. Rebouta, E. Alves, Ph. Goudeau, J.P. Riviere, Surface and Coatings Technology, 200 (2006) 6634-6639.

15.E. Ariza, L.A. Rocha, F. Vaz, L. Cunha, S.C. Ferreira, P. Carvalho, L. Rebouta, E. Alves, Ph. Goudeau, J.P. Riviere, Thin Solid Films, 469-470 (2004) 274-281.

16. European Standard EN 1811:1998. Reference test method for release of nickel from products intended to come into direct and prolonged contact with the skin.

17. J.R. Scully, Corrosion, 56 (2000) 199-218.

18. A.C. Fernandes, P. Carvalho, F. Vaz, S. Lanceros-Méndez, A.V. Machado, N.M.G. Parreira, J.F. Pierson and N. Martin, Thin Solid Films 515 (2006) 866.

19. P. Jemmely, S. Mischeler, D. Landolt, Tribology International 32 (1999) 295303. 
20.P. Pontiaux, F. Wenger, D. Drees, J.P. Celis, Wear 256 (2004) 459-468.

21. Archard. J.F., Contact and rubbing of flat surfaces, J. Appl. Phys. 24 (1953) 981

22.Z. Yue, P. Zhou, J. Shi, in Luedema K.C. Ed., Proc. Conf. Wear of Materials, ASME, New York, (1987), 763-768.

23. M.M. Stack, S. Zhou, R.C. Newman, Mater. Sci. Tech (1996) 12, 261-268

24. M.M. Stack, N. Pungwiwat, Wear (2004) , 256, 5, 565-576

25. M.M. Stack, K. Chi, Wear (2003) 255, 456-465

26. M. Ziomek-Moroz, A. Miller, J. Hawk, K. Cadien, D.Y. Li, Wear 255 (2003) 869-874.

27. M. Godet, Y. Berthier, J. Lancaster, Wear 1991, 149-325

28. J.A. Williams, A.M. Hyncica, J.Phys.D:Appl.Phys., 25 (1992) A81-A90

29. N. Axen, S. Jacobson,S. Hogmark, Tribology International, 274 (1994) 233241

30. J.M. Guiemany, J.M. Miguel, S. Vizcaino, F. Climent, Surface and Coatings Technology, 140 (2001) 141-146.

31. W. Hirst, J.K. Lancaster, Journal of Applied Physics, 27 (1956) 1057-65

32. R.D.J. Haworth, The abrasion Resistance of metals, Trans. ASM., 41 (1949) 819-869.

33. A. Umeda, J. Sugimura, Y. Yamamoto, Wear 216(1998) 22-228

34. H. Zhang, D.Y. Li, Wear 255 (2003) 924-932

35. Pie-Qiang Wu, J.P. Celis, Wear 256 (2004) 480-490.

36. M. Sasaki, I. Nakamura, I. Takano, Y. Sawada, Electrical Engineering in Japan, 1493 (2004) 1-7.

\section{Table Captions}

1. Details of the $\mathrm{TiC}_{\mathrm{x}} \mathrm{O}_{\mathrm{y}}$ films considered in the tests

2. Composition of artificial sweat solution 
3. Individual contributions of corrosion and wear to the total wear loss.

\section{Figure Captions}

1. Schematic diagram of reciprocating pin/plate tribometer and electrochemical cell used in the test.

2. Micrographs and AFM images

(a) Plane surface of $f_{\mathrm{O}}=1$

(b) Worn surface of $f_{\mathrm{O}}=0.97$ showing a pit

(c) Micrograph of corroded surface of $f_{\mathrm{O}}=0.33$, showing the influence of pitting potential

(d) Micrograph of corroded surfaces of $f_{\mathrm{O}}=0.97$, showing the influence of pitting potential

3. SEM images

(a) Pin mark on the surface of $f_{\mathrm{O}}=0.35$

(b) Cracks and special regime formed on the worn surface.

(c) Boundary of the wear path with high magnification $\left(f_{\mathrm{O}}=0.67\right)$

(d) Crack and special regime on $f_{\mathrm{O}}=0.33$

(e) Clear boundary on $f_{\mathrm{O}}=0.92$

(f) Completely removed $f_{\mathrm{O}}=1$

4. Potentiodynamic polarization curves obtained for some representative $\mathrm{TiC}_{\mathrm{x}} \mathrm{O}_{\mathrm{y}}$ films immersed in artificial sweat solution.

5. Variation of corrosion current and friction coefficient with sliding time for

(a) $f_{\mathrm{O}}=0.55$ and (b) $f_{\mathrm{O}}=0.79$

6. EIS results obtained for some representative $\mathrm{TiC}_{\mathrm{x}} \mathrm{O}_{\mathrm{y}}$ films $\left(f_{\mathrm{O}}=0.33, f_{\mathrm{O}}=0.97\right.$ and $f_{\mathrm{O}}=1$ ) before and after sliding processes. 
(a) Bode Z plot (Frequency vs. Impedance modulus $|\mathrm{Z}|$ ),

(b) Bode phase plot (Frequency vs. Phase angle).

7. (a) Evolution of the polarization resistance $\left(R_{p}\right)$ and film thickness with the oxygen fraction, before and after sliding time,

(b) Evolution of the film capacitance and film thickness with the oxygen fraction, before and after sliding time,

(c) Evolution of the polarization resistance and number of defects with the oxygen fraction, before and after sliding time.

8. Variation of wear-corrosion volume in relation to film thickness, hardness and depth of the wear profile.

9. Two types of situation s after the wear-corrosion test.

(a) Worn profile with retention of film.

(b) Worn profile reaching to the substrate.

10. Contribution of corrosion $\left(\mathrm{K}_{\mathrm{c}}\right)$ and wear $\left(\mathrm{K}_{\mathrm{w}}\right)$ to total wear volume loss $\left(\mathrm{K}_{\mathrm{wc}}\right)$. 11. Schematic diagram of the tribocorrosion process showing various regions in the contact zone. 


\begin{tabular}{|c|c|c|c|c|c|c|c|}
\hline \multicolumn{7}{|c|}{ Table 1 Details of the $\mathbf{T i C}_{\mathbf{x}} \mathbf{O}_{\mathbf{y}}$ films considered in the tests } \\
\hline Sample & $\begin{array}{c}\text { Oxygen } \\
\text { fraction } \\
\left(f_{\mathrm{O}}\right)\end{array}$ & $\begin{array}{c}\mathbf{T h i c k n e s s} \\
(\boldsymbol{\mu} \mathbf{m})\end{array}$ & $\begin{array}{c}\mathbf{T i} \\
(\mathbf{a t .} \%)\end{array}$ & $\begin{array}{c}\mathbf{C} \\
(\mathbf{a t . \% )}\end{array}$ & $\begin{array}{c}\mathbf{O} \\
(\mathbf{a t . \% )}\end{array}$ & $\begin{array}{c}\text { Hardness } \\
(\mathbf{G P a})\end{array}$ & $\begin{array}{c}\text { Number of } \\
\text { defects/mm }\end{array}$ \\
\hline $\mathrm{TiC}_{0.28} \mathrm{O}_{0.14}$ & 0.33 & $6.3 \pm 0.7$ & 70.3 & 19.8 & 9.9 & 3.2 & - \\
\hline $\mathrm{TiC}_{0.32} \mathrm{O}_{0.17}$ & 0.35 & $4.8 \pm 0.3$ & 67.1 & 21.5 & 11.4 & 6.8 & - \\
\hline $\mathrm{TiC}_{0.36} \mathrm{O}_{0.45}$ & 0.55 & $5.8 \pm 0.2$ & 55.2 & 20.0 & 24.8 & 10.0 & 415 \\
\hline $\mathrm{TiC}_{0.37} \mathrm{O}_{0.76}$ & 0.67 & $5.2 \pm 0.2$ & 46.9 & 17.4 & 35.7 & 14.8 & 171 \\
\hline $\mathrm{TiC}_{0.40} \mathrm{O}_{1.52}$ & 0.79 & $4.4 \pm 0.1$ & 34.3 & 13.8 & 51.9 & 17.0 & 197 \\
\hline $\mathrm{TiC}_{0.14} \mathrm{O}_{1.51}$ & 0.92 & $5.8 \pm 0.2$ & 37.8 & 5.3 & 56.9 & 13.6 & - \\
\hline $\mathrm{TiC}_{0.07} \mathrm{O}_{2.31}$ & 0.97 & $1.5 \pm 0.4$ & 29.6 & 1.9 & 68.5 & 9.2 & 99 \\
\hline $\mathrm{TiO}_{2}$ & 1 & $1.2 \pm 0.4$ & 33.3 & 0 & 66.6 & 9.6 & 596 \\
\hline
\end{tabular}




Table 2 Composition of artific ial sweat solution [16].
\begin{tabular}{l|l}
\hline Components & Composition \\
\hline $\mathrm{NaCl}$ & $7.5{\mathrm{~g} . \mathrm{L}^{-1}}^{-1}$ \\
$\mathrm{KCl}$ & $1 \mathrm{~g} . \mathrm{L}^{-1}$ \\
\hline $\mathrm{CH}_{4} \mathrm{~N}_{2} \mathrm{O}$ (Urea) & $1 \mathrm{~g} . \mathrm{L}^{-1}$ \\
$\mathrm{C}_{3} \mathrm{H}_{6} \mathrm{O}_{3}$ (Lactic acid) & $1 \mathrm{ml} . \mathrm{L}^{-1}$ \\
\hline $\mathrm{NH}_{3}$ added to adjust the pH of 4.49
\end{tabular}




\begin{tabular}{|c|c|c|c|c|}
\hline \multicolumn{5}{|c|}{ Table 3 Wear volume loss data by corrosion and wear } \\
\hline Films & $\begin{array}{c}\text { Kc }\left(\mathbf{m m}^{\mathbf{3}}\right) \\
* \mathbf{1 0}^{-5}\end{array}$ & $\begin{array}{c}\text { Kwc }\left(\mathbf{m m}^{\mathbf{3}}\right) \\
* \mathbf{1 0}^{-\mathbf{2}}\end{array}$ & $\begin{array}{c}\text { Kw }\left(\mathbf{m m}^{\mathbf{3}}\right) \\
* \mathbf{1 0}^{-\mathbf{2}}\end{array}$ & $\begin{array}{c}\mathbf{K c} / \mathbf{K w} \\
* \mathbf{1 0}^{-3}\end{array}$ \\
\hline$f_{\mathrm{O}}=0.33$ & 3.98 & 2.33 & 2.34 & 1.7 \\
\hline$f_{\mathrm{O}}=0.55$ & 5.01 & 1.38 & 1.38 & 3.6 \\
\hline$f_{\mathrm{O}}=0.67$ & 1.46 & 1.88 & 1.88 & 0.8 \\
\hline$f_{\mathrm{O}}=0.79$ & 3.99 & 1.36 & 1.36 & 2.9 \\
\hline$f_{\mathrm{O}}=0.92$ & 9.22 & 2.23 & 2.22 & 4.2 \\
\hline
\end{tabular}




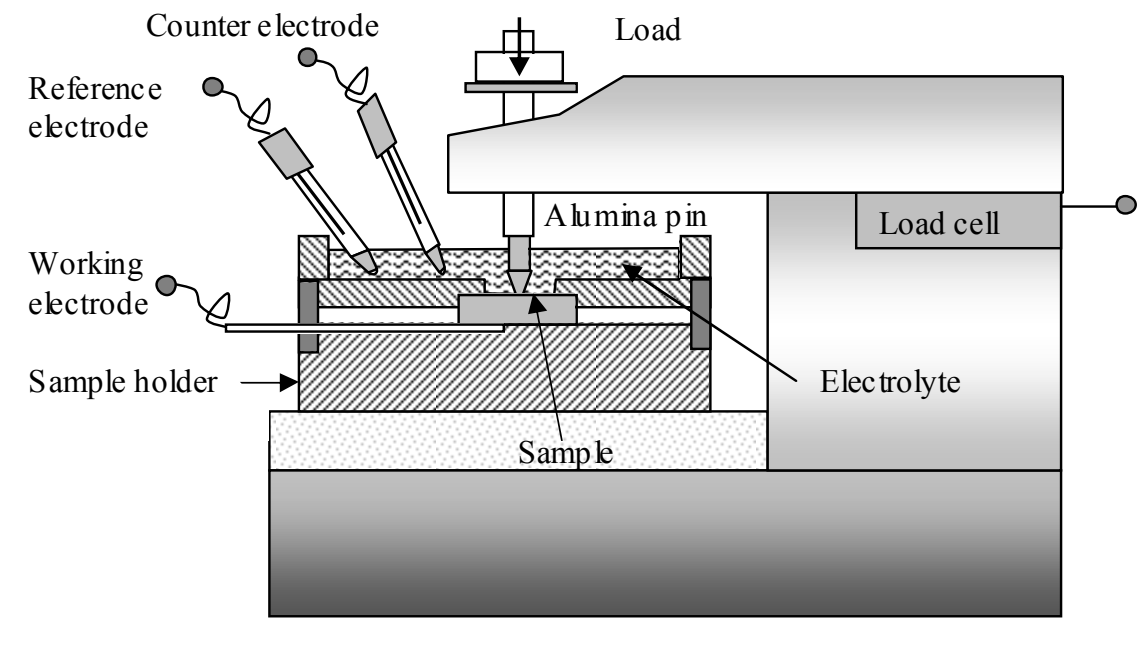

Figure 1

Figure 1

\section{Figure(s)}

Reference
electrode

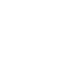




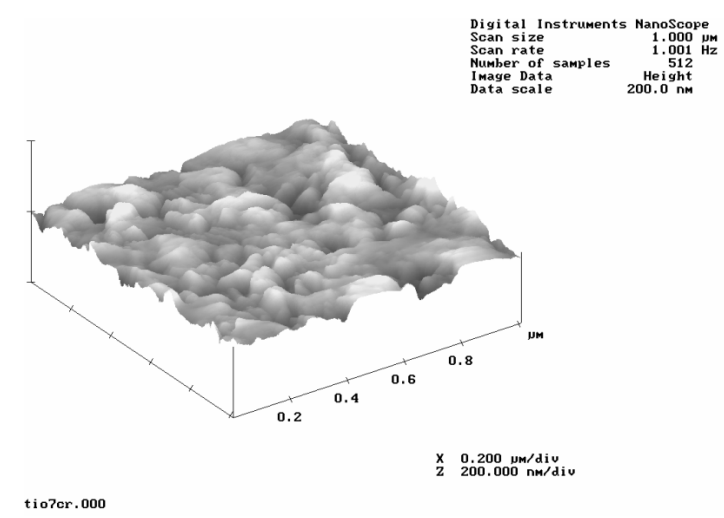

(a)

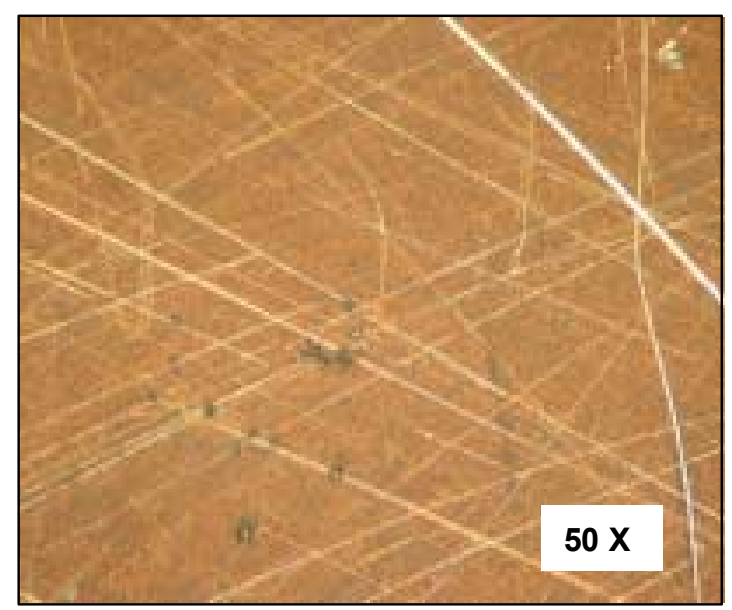

(c)

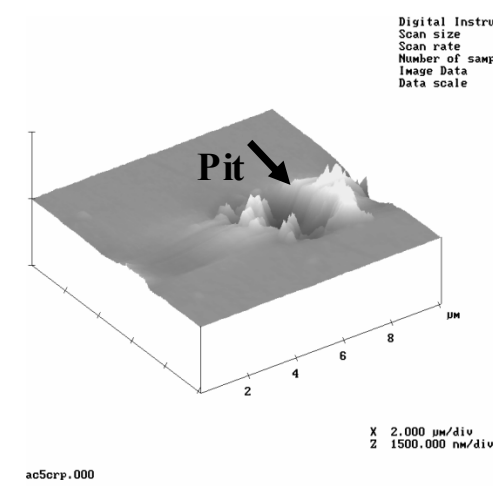

(b)

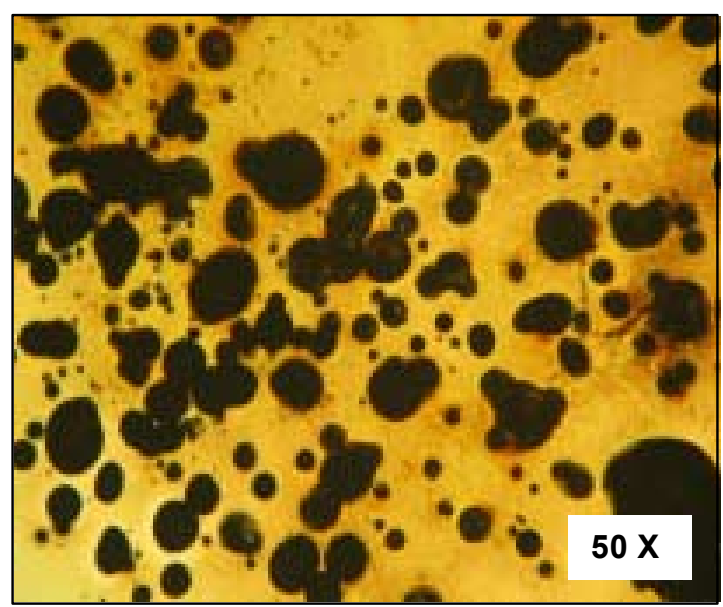

(d)

Figure 2 (a-d) 


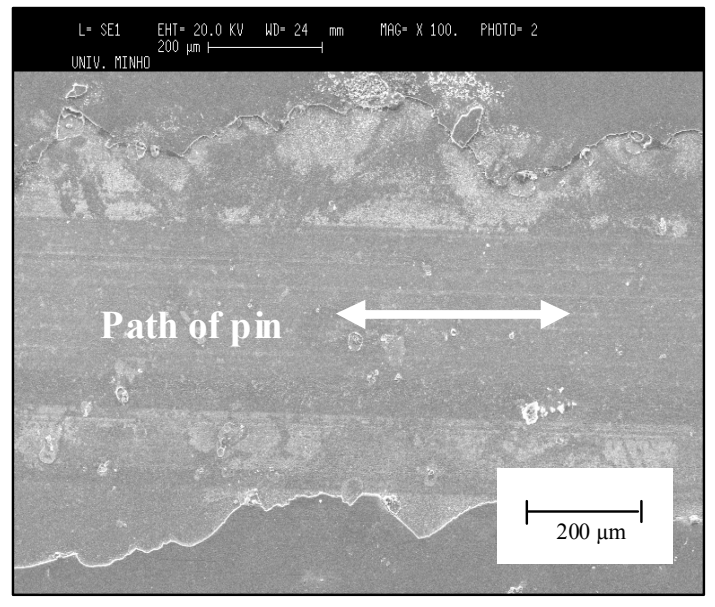

(a)

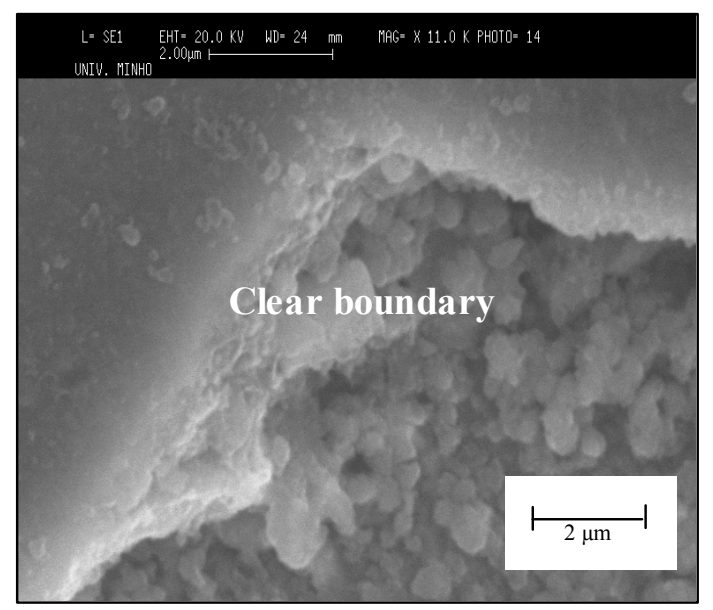

(c)

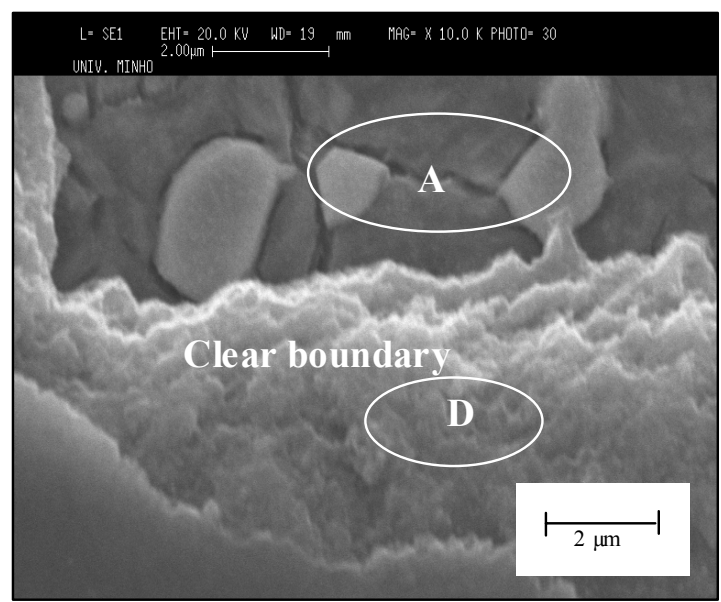

(e)

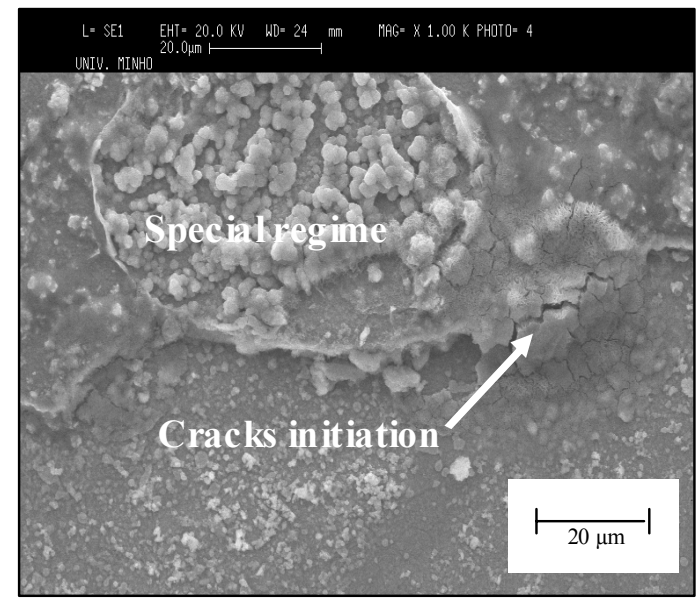

(b)

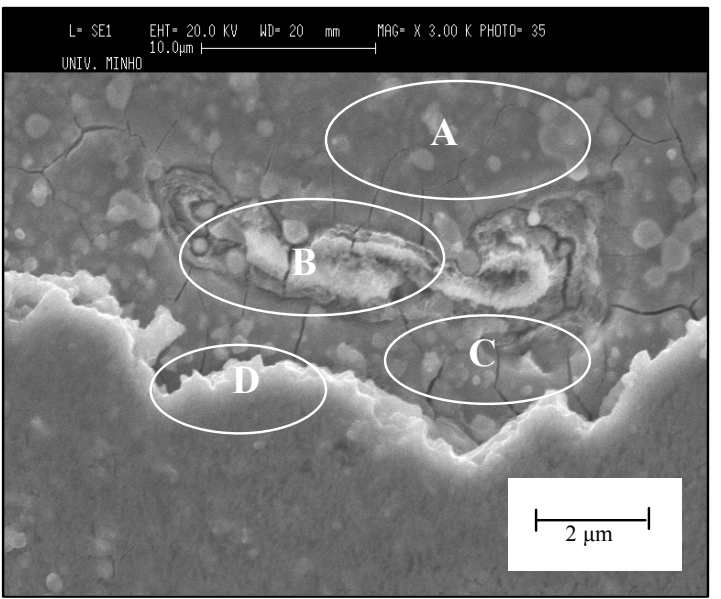

(d)

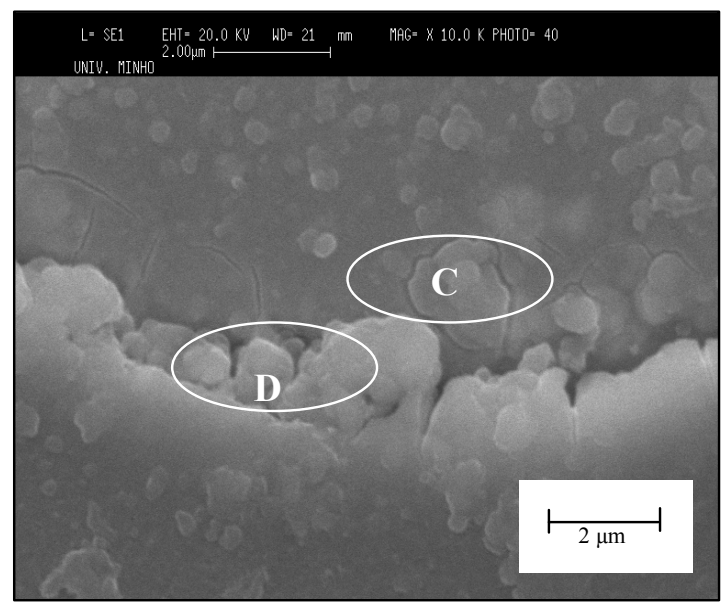

(f)

Figure 3 (a-f) 


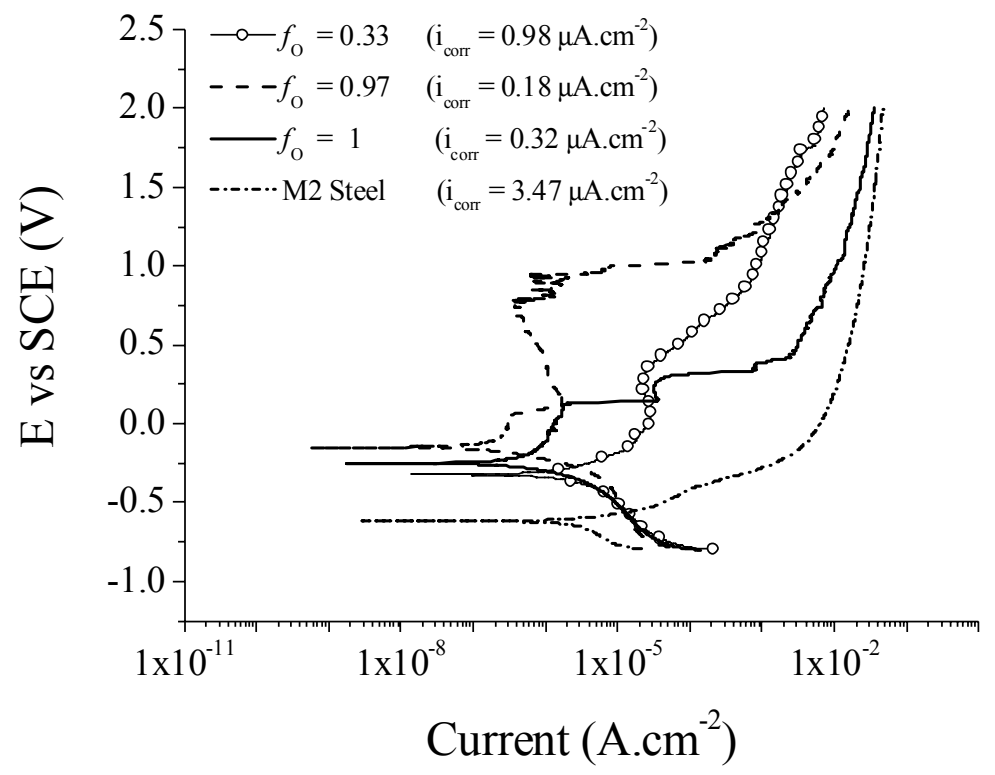

Figure 4 


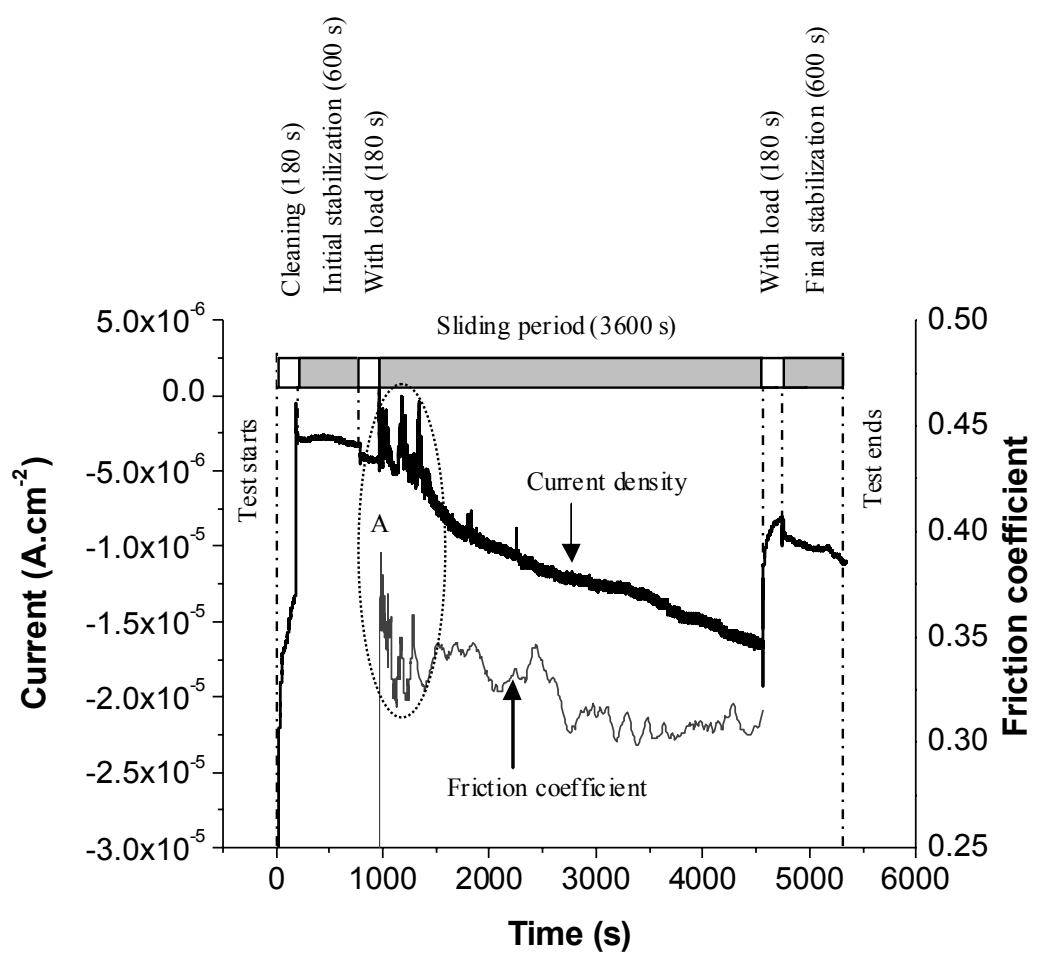

(a)

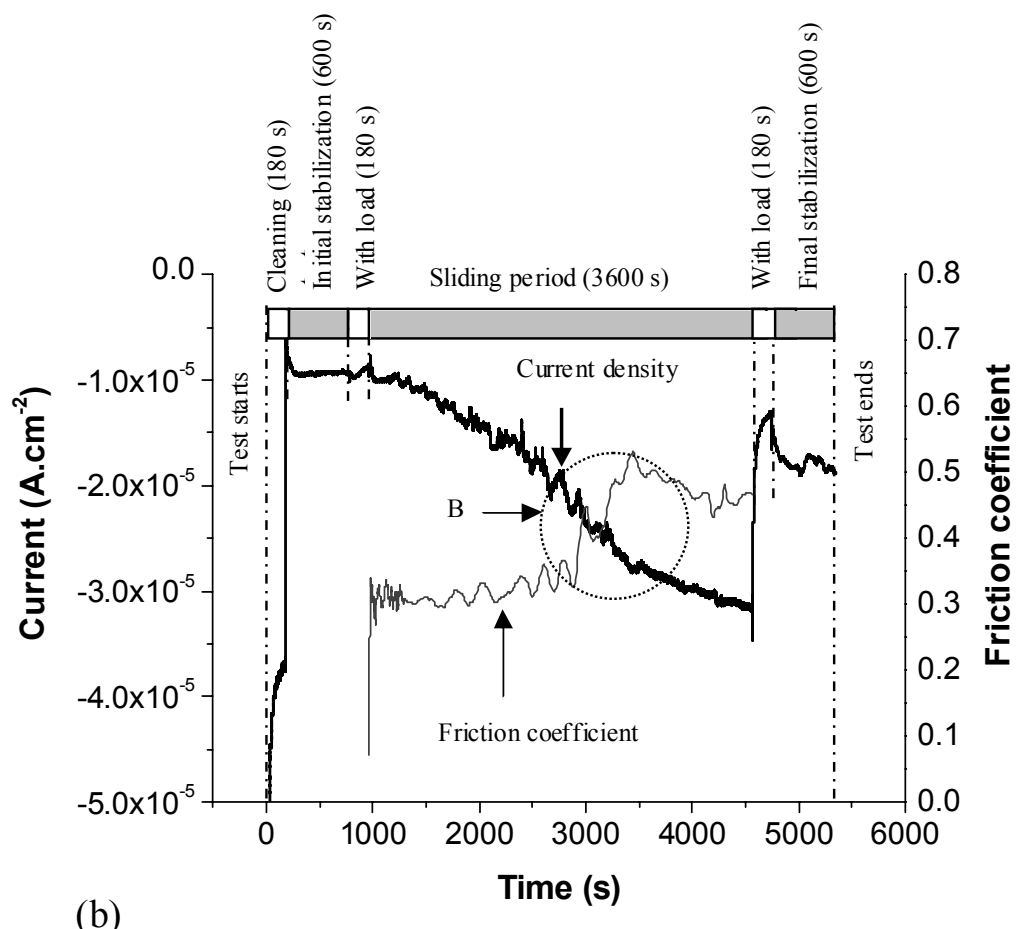

Figure 5(a-b) 


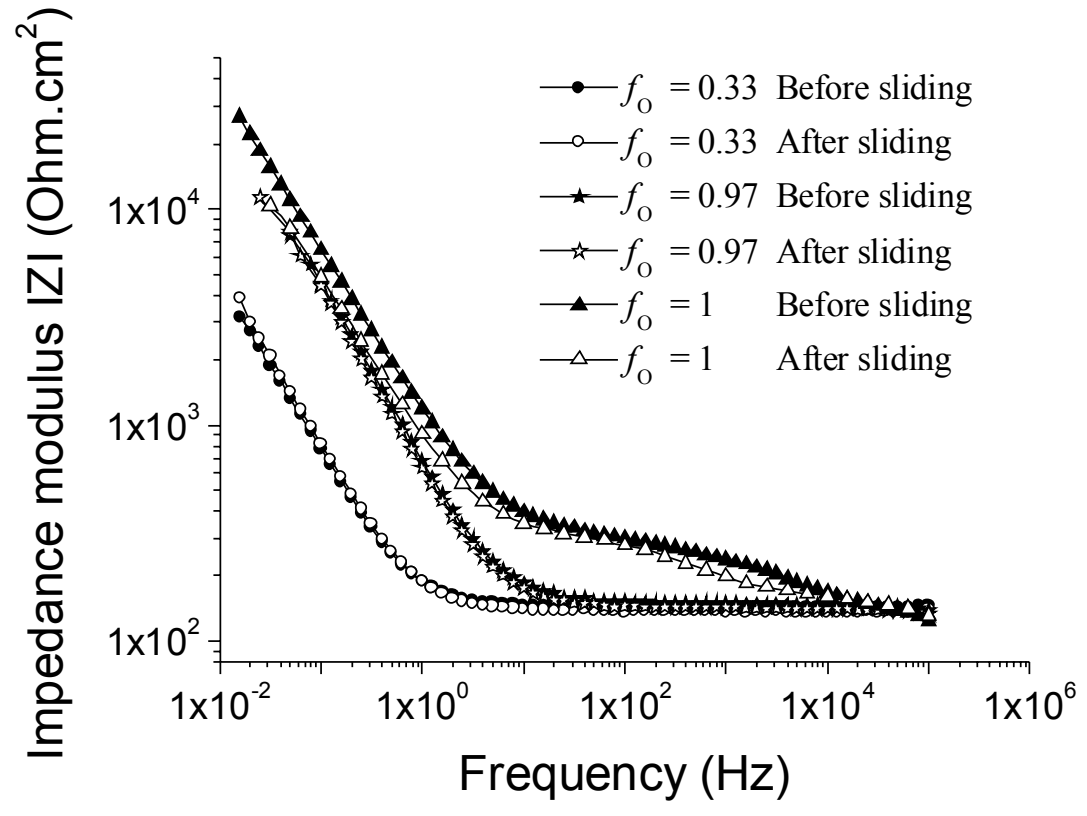

(a)

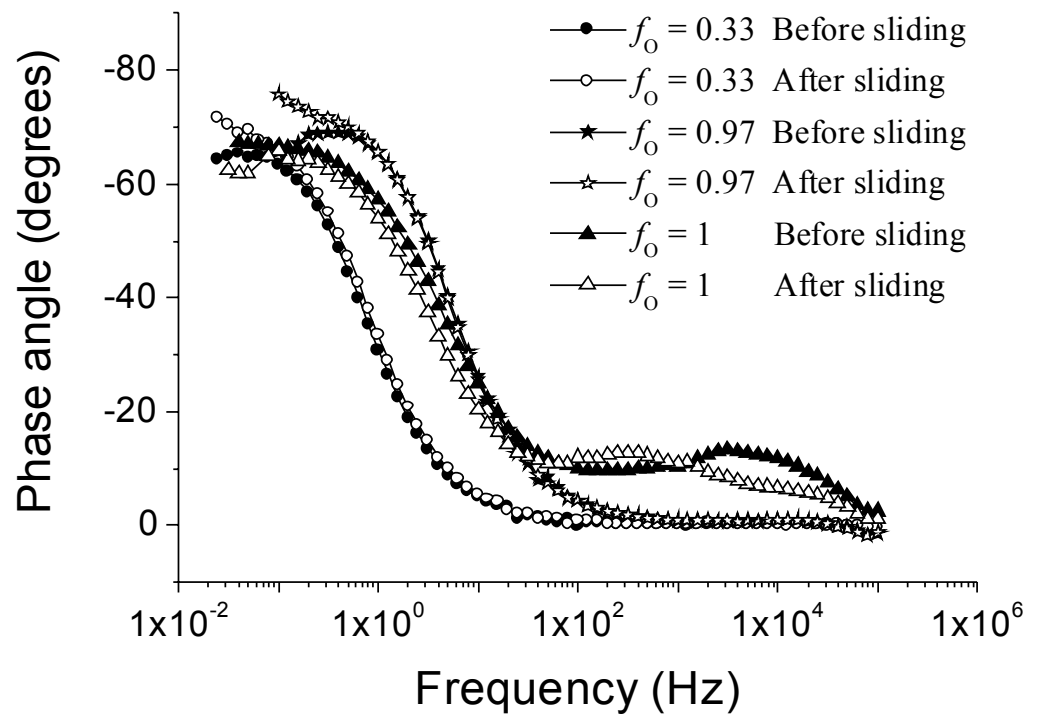

(b)

Figure $6(a-b)$ 


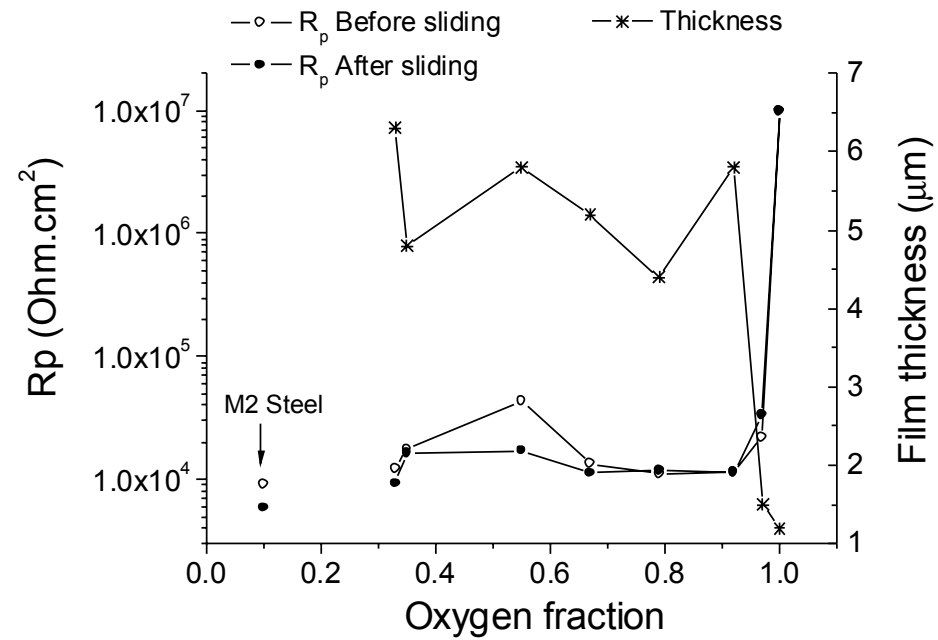

(a)

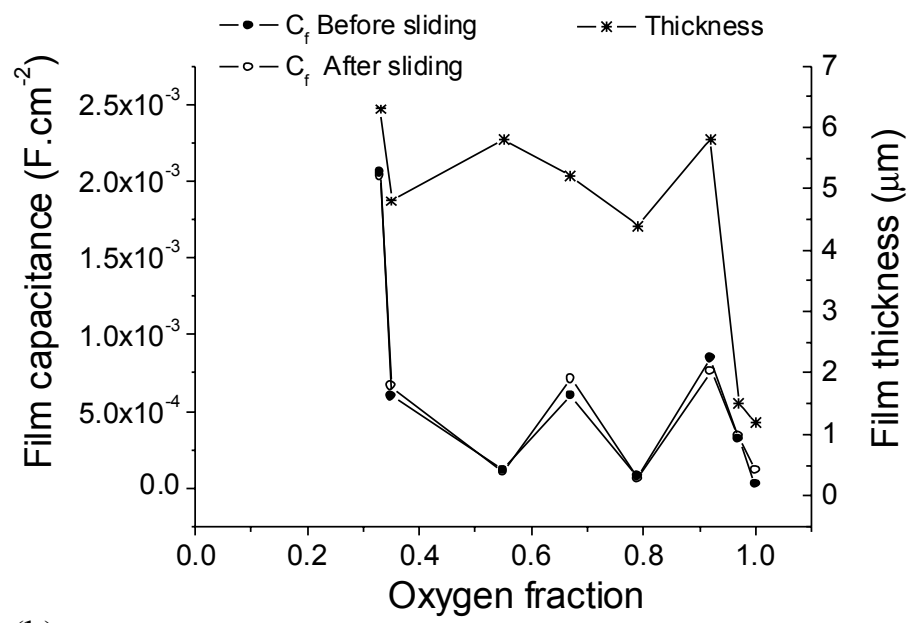

(b)

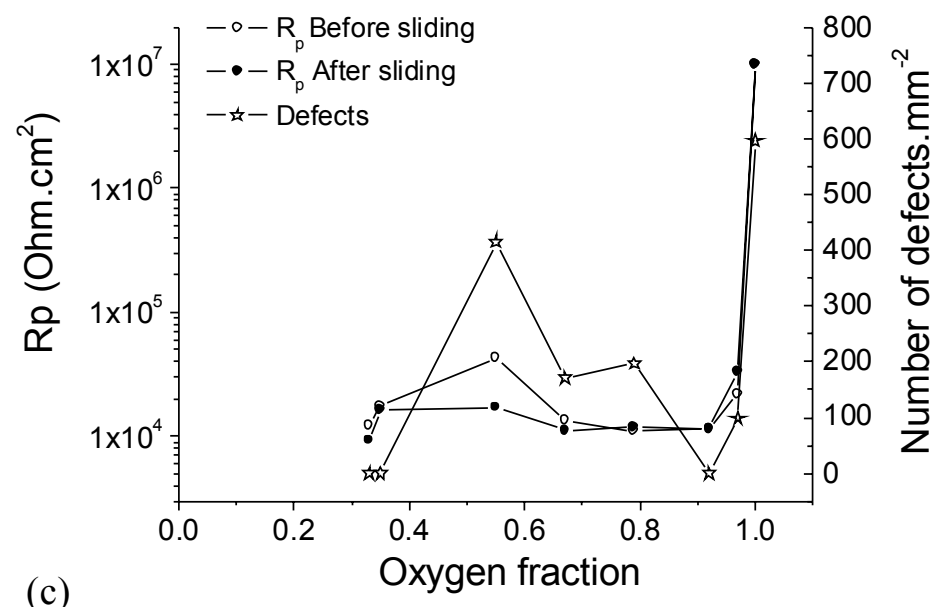

Figure 7 (a-c) 


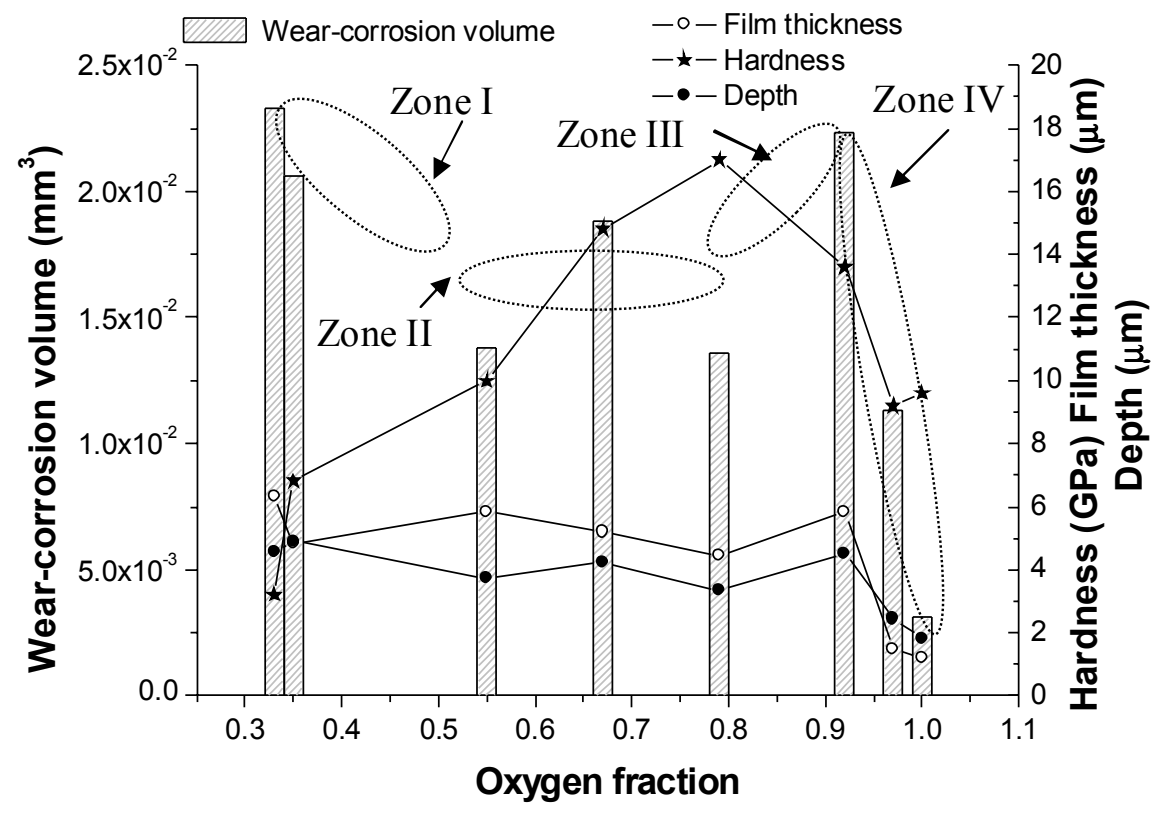

Figure 8 


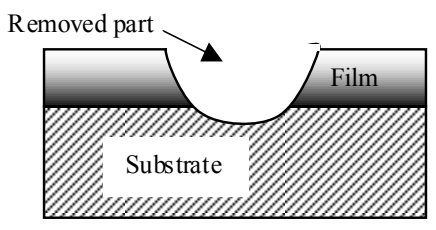

(a)

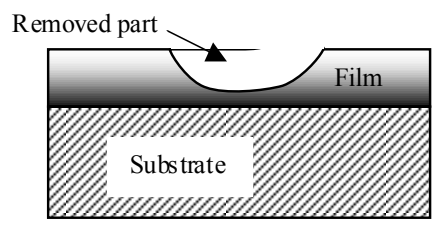

(b)

Figure $9(a-b)$ 


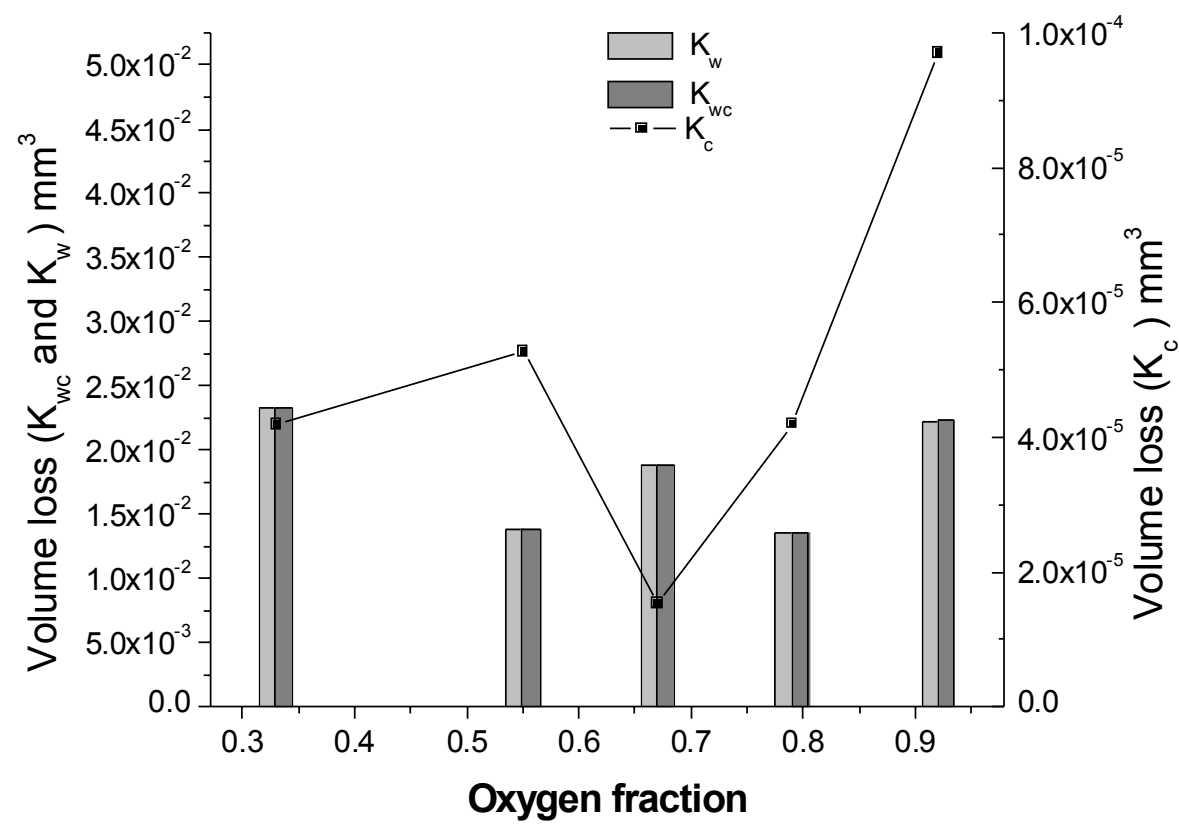

Figure 10 


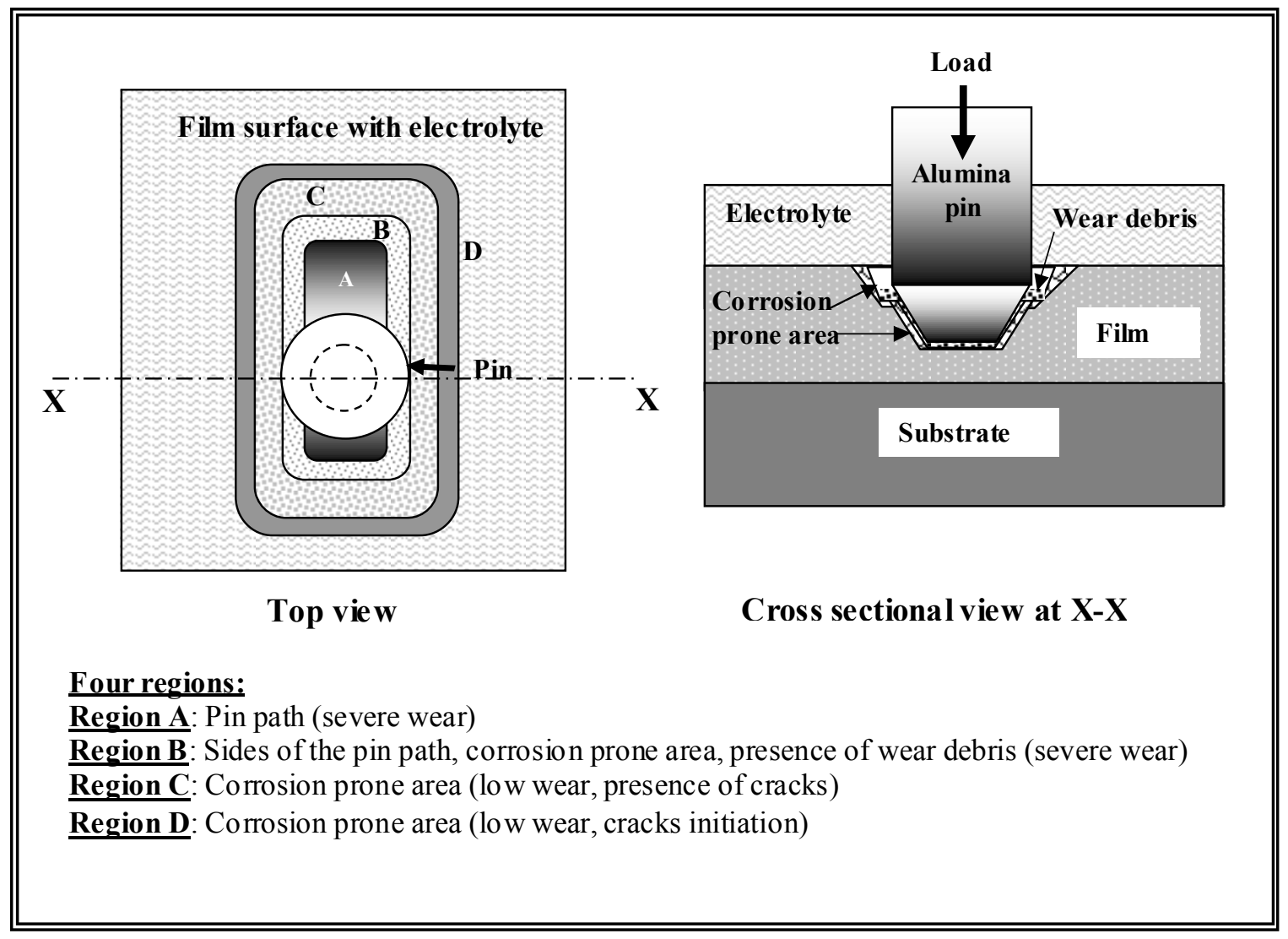

Figure 11 